\title{
The Legacy of the Great Recession in Italy: A Wider Geographical, Gender, and Generational Gap in Working Life Expectancy
}

\author{
Angelo Lorenti $^{1}$ (D) Christian Dudel ${ }^{1} \cdot$ Mikko Myrskylä $^{1,2,3}$
}

Accepted: 27 April 2018 / Published online: 8 May 2018

(C) The Author(s) 2018

\begin{abstract}
Under the pressure of population aging the Italian pension system has undergone reforms to increase labor force participation and retirement age, and, thus, the length of working life. However, how the duration of working life has developed in recent years is not well understood. This paper is the first to analyze trends in working life expectancy in Italy. We use data from a nationally representative longitudinal sample of 880,000 individuals from 2003 to 2013 and estimate working life expectancy by gender, occupational category, and region of residence using a Markov chain approach. We document large and increasing heterogeneity in the length of working life. From 2003-2004 to 2012-2013, working life expectancy for men declined from 35.2 to 27.2 years and for women from 34.7 to 23.7 years, increasing the gender gap to 3.5 years. Both young and old were hit, as roughly half of the decline was attributable to ages below 40, half above 40 . Working life expectancy declined for all occupational groups, but those in manual occupations lost most, 8.5 years (men) and 10.5 years (women). The North-South economic gradient widened such that men living in the North were expected to work 8 years longer than women living in the South. The fraction of working life of total life expectancy at age 15 declined to record lows at $40 \%$ for men and 34\% for women in 2012-2013. Policies aiming
\end{abstract}

Electronic supplementary material The online version of this article (https://doi.org/10.1007/s1120 5-018-1910-7) contains supplementary material, which is available to authorized users.

Angelo Lorenti

lorenti@demogr.mpg.de

Christian Dudel

dudel@demogr.mpg.de

Mikko Myrskylä

myrskyla@demogr.mpg.de

1 Max Planck Institute for Demographic Research, Konrad-Zuse-Str. 1, 18057 Rostock, Germany

2 Department of Social Policy, London School of Economics and Political Science, London, UK

3 Population Research Unit, University of Helsinki, Helsinki, Finland 
at increasing total population working life expectancy need to take into consideration the socio-demographic disparities highlighted by our results.

Keywords Working life expectancy $\cdot$ Great recession $\cdot$ Italy $\cdot$ Financial crisis $\cdot$ Working life table $\cdot$ Multistate life table

\section{Introduction}

The financial crisis of 2007-2008 and its consequences have led to an increased interest in the economic impact of population aging. The unexpected decline in contributions to public pensions due to the rise in unemployment and the tremendous losses reported by pension funds have placed additional strain on social security systems (Keeley and Love 2010), which were already under pressure because of the growth in both the number of pension recipients and the length of time people receive pension payments. As negative effects from the recession and population aging are widespread phenomena, increased burdens on social security systems are common among developed countries (OECD 2015b). To deal with the consequences of the crisis, many countries are attempting to limit public pension expenditures. Thus, implementing policies aimed at increasing the duration of working life has become a high priority in these countries (OECD 2013).

Understanding work-life patterns and how individual socio-demographic characteristics affect working trajectories is of paramount importance. Surprisingly, very little is known about which factors determine the length of working life and how it interacts with the economic environment, as many studies focus only on specific phases of and transitions in the life course, and do not assess its entirety (Dudel and Myrskylä 2017). An indicator that allows us to take a holistic perspective and to assess complete working trajectories is working life expectancy. Working life expectancy (WLE) is the expected years of life spent in employment (e.g.); i.e., the average number of years spent in employment over the life course. Several slightly differing definitions of and alternative terms for WLE are used in the literature, such as worklife expectancy or labor market life expectancy (Hoem 1977; Loichinger and Weber 2016). WLE summarizes the length of working trajectories in a single number, and is thus a useful indicator of the sustainability of pension systems and labor markets in general. In addition, it provides insights into labor market inequalities, as it shows how labor market (dis)advantages accumulate (Hayward and Lichter 1998).

In this paper, we use longitudinal social security register data from Italy for the years 2003-2013 to estimate working life expectancy and other related indicators: the years of life spent in retirement, the years of life spent in unemployment, and the years of life spent in inactivity out of the labor market. These measures are provided by gender, occupation, and region of residence. The full working life cycle from age 15 onward is considered. Our results allow for the analysis of recent trends in WLE in Italy, and of how WLE was affected by the financial crisis. Exploiting the longitudinal nature of the data, we estimate WLE using working life tables based on discrete-time Markov chains and discrete-event history analysis. The method is based on the probabilities of moving between different labor force states (e.g., employed, unemployed, retired) which are used to derive the expected time spent in each of these states.

We contribute to the literature in several ways. First, to the best of our knowledge, we are the first to provide working life tables for Italy. Second, most previous studies on WLE have focused on working trajectories in old age shortly before retirement, whereas we 
report results that cover the full life cycle. Third, we add to the growing literature on the consequences of the financial crisis by assessing its impact on WLE and on labor market inequalities in an aging country. For this purpose, Italy is an interesting case study. Although it is among Europe's largest economies, Italy has been severely affected by the financial crisis. Moreover, the country has an older population and a high incidence of early retirement (see Sect. 2). Of particular interest in this context is the sharp segregation of the Italian labor market into a two-tier structure, which is associated with large inequalities in labor market opportunities (Barbieri et al. 2016). It also appears that these opportunity gaps have been aggravated by the recession, with vulnerable groups being hit especially hard. Thus, heterogeneity in WLE may have increased in recent years. Fourth, we are the first to provide estimates of WLE at the regional level, as previous studies on this topic provided national estimates only. Italy is again an interesting case study for such an analysis, as the country is known for having strong regional disparities in labor market performance (O'Higgins 2011). Overall, our study sheds light on the consequences of the financial crisis in the context of an aging population by examining the effects of the recession on working trajectories, and on the heterogeneity of these effects.

The paper is organized as follows. Literature on WLE and the Italian labor market and welfare state are described in Sect. 2. Section 3 presents the data. Section 4 outlines the methods. Section 5 describes the results, and Sect. 6 discusses our findings. Section 7 concludes.

\section{Background}

\subsection{Working Life Expectancy}

In Europe, WLE has been previously studied for a limited number of countries only: Denmark (Hoem 1977); the UK (Butt et al. 2008, 2010; Haberman and Bloomfield 1990); Finland (Leinonen et al. 2015; Nurminen et al. 2005); and, recently, Spain (Dudel et al. 2018). Estimates for a longer list of countries are routinely published by Eurostat (Loichinger and Weber 2016), but are built on prevalence based Sullivan's method, which can produce severely biased estimates in particular if the incidence rates are changing (e.g. Mathers and Robine 1997). By contrast, the papers mentioned above use working life tables based on transition data and Markov processes (see Sect. 3).

Findings from the European literature indicate that WLE tends to be shorter for females than for males, and that higher occupational groups have longer WLE. Moreover, there appear to be considerable differences in WLE by country. Nurminen et al. (2005) estimated that in Finland in 2006, WLE at age 16 was 29.7 years for females and 31.4 years for males. In contrast, for Spain in 2011/2012 - after the country was hit hard by the recession-WLE at age 16 was estimated at 24.7 years for females and 28.8 for males. Remaining WLE at age 50 was estimated at 7.9 years for females and 8.9 for males in Spain and at 10.0 years for females and 9.1 years for males in Finland (Leinonen et al. 2015). WLE has been shown to be higher in the U.S. than in Europe. Dudel and Myrskylä (2017) reported that in the period from 2008 to 2011, WLE at age 50 in the U.S. was 11 years for females and roughly 13 years for males. Among the explanations given for these discrepancies in WLE are that retirement is a less clearly defined event in the U.S. than it is in Europe, and that it is not uncommon for Americans to return to employment after retirement (e.g., Cahill et al. 2006; Hayward et al. 1994). 
Literature on group differences in WLE document strong gradients by occupation (Dudel et al. 2018), social class (Leinonen et al. 2015), and educational attainment (Liefbroer et al. 1999), consistently such that higher social class is associated with a longer WLE. Studies on WLE for the U.S. context mainly focused on white/non-white differentials. Smith (1986) and Hayward and Grady (1990) found that WLE was higher among whites than among non-whites, and that the differences in WLE were greater among males than among females. Millimet et al. (2003) documents that the gap between whites and non-whites decreases with age and education. More recent studies have confirmed previous findings of WLE gaps between individuals of different genders (Warner et al. 2010), different races, and different educational levels (Dudel and Myrskylä 2017). Skoog and Ciecka (2010) studied long-term trends in WLE using data from the Current Population Survey (CPS). They found that the gains in life expectancy from 1970 to 2003 were spent almost entirely in retirement for males, but not for females.

\subsection{The Italian Context}

In 2015, the share of the population aged 65 and older was, at $21.7 \%$, the highest in Europe; while the share of the population aged 14 and younger was very low, at $13.8 \%$ (Eurostat 2017a). The share of the country's GDP spent on public pensions in 2015 was, at $15.8 \%$, among the highest in the world (OECD 2015b). This high level of pension expenditures is a consequence of the past structure of the pension system, which had, until recently, provided high replacement rates and the option to retire at very young ages. For a period of more than 30 years, the retirement age was declining in Italy (OECD 2015b). This pattern was largely the result of policies in effect from the 1970s to the mid-1990s that provided incentives for early retirement (Brugiavini 2001).

The Italian pension system is based on three pillars: the first is a mandatory public pension scheme, while the other two are supplementary non-mandatory pension schemes. The mandatory scheme is the most important, as it covers almost all private and public employees. Since the beginning of the 1990s, several reforms have been introduced that aimed at shoring up the financial viability of the pension system. Before the 2011 reform, eligibility for a seniority pension was based on having at least 40 years of contributions, but there were no minimum age requirements. Alternatively, workers who had at least 35 years of contributions could qualify to receive a seniority pension, provided the sum of their age and years of contributions was equal to 92 . The normal pension eligibility age for individuals with at least 20 years of contributions was 65 for men and 60 for woman. These eligibility standards have, however, been adjusted several times over the course of the reform process.

From 1992 to 2011, the main aims of the reform process were to increase the statutory retirement age and to turn the defined benefit (DB) pension plan system into a defined contribution (DC) retirement plan system. Until recently, most of these adjustments had long transitional periods and were implemented slowly. Thus, the short-term effects of these reforms were very limited. By contrast, the so-called "Monti-Fornero reform" (Law 214/2011) introduced in 2011 had an immediate impact. Since the most recent year in our data is 2013 , the changes introduced by the Fornero reform legislation will not be reflected in our results.

These important changes were accompanied by labor market developments and policy reforms relevant to the beginning and the middle stages of working life: namely, increased female labor force participation (Scherer and Reyneri 2008); delayed labor market entry 
because of more time spent in education (Billari and Rosina 2004; Billari and Tabellini 2010); labor market deregulation (Aricò and Stein 2012; Cirillo et al. 2017); and a trend toward discontinuous employment and career trajectories among people of working ages (Barbieri and Scherer 2009). Despite these shifts, by Italian standards the country's labor market conditions before the crisis were generally considered favorable (Aricò and Stein 2012), including for young people entering the labor market (Mussida and Sciulli 2016).

While these developments affected the whole country, there are large and longstanding regional disparities in economic conditions across Italy. There is a North-South gradient in economic prosperity, whereby the South of Italy ("Mezzogiorno") has always had higher levels of unemployment than the rest of the country (e.g., Reyneri 2002; Taylor and Bradley 1997). This gap is due in part to the heavy concentration of industrial production in the North of Italy (O'Higgins 2011).

The impact of the financial crisis on the labor market was large (Arpaia et al. 2010). Measured in terms of relative decline in GDP, Italy went in and out of recession between mid-2007 and early 2013 (OECD 2017). The unemployment rate rose from 5.6\% in mid2007 to $13.5 \%$ in the first quarter of 2014 (Eurostat 2017b). Following the onset of the crisis, economic insecurity levels (D’Ambrosio and Rohde 2014) and health risks (Sarti and Zella 2016) increased rapidly, while consumption decreased (Bono et al. 2016). Italian youth were hit particularly hard by the crisis: both short- and long-term youth unemployment increased, and many of the young people who eventually found jobs were employed under temporary contracts (O'Higgins 2012). These trends might be indicative of an increase in unstable work trajectories, and thus of a major change in the Italian labor market, since before the crisis most labor market entrants could find stable jobs, despite labor market deregulation (Scherer 2005). Regional disparities were exacerbated by the crisis, and unemployment in the South of Italy rose drastically (O'Higgins 2011).

It is highly likely that these changes in labor market conditions and trajectories are affecting the length of working life. Based on previous findings on WLE, we can assume that the recent developments in Italy are associated with large declines in WLE. Differentials in the employment rates of males and females should be reflected in WLE, but might have decreased, as the gap between male and female unemployment rates appears to have closed, at least during the beginning of the recession (e.g., O'Higgins 2011). Moreover, losses in WLE due to the crisis might be more concentrated at younger ages (Dudel et al. 2018; O'Higgins 2012). We can also expect to observe regional differences in WLE both before and during the crisis, with the changes in WLE being especially large in the South, which has been more affected by the crisis than the rest of the country (Lagravinese 2015).

\section{Data}

The length of working life and related measures, such as the time spent in retirement, depend on the years of life spent in each of the various labor force states. To estimate working life expectancy (WLE), we need detailed information on each individual's movements in and out of the labor force, and on individual mortality. We use data from the Longitudinal Sample INPS (LoSaI) ${ }^{1}$ provided by the National Institute of Social Security (INPS) and the Ministero del Lavoro e delle Politiche Sociali, which has recently been made publicly

\footnotetext{
${ }^{1}$ https://www.cliclavoro.gov.it/Barometro-Del-Lavoro/Pagine/Microdati-per-la-ricerca.aspx.
} 
available. The INPS is responsible for collecting the social security contributions of almost all employees and self-employed workers (except for freelance professionals, who make contributions to other institutions), and for paying out pension benefits. The social security contribution rates vary across economic sectors. Employers make contributions to the INPS on behalf of their workers, and withhold the employee share of social security contributions from their gross earnings. If an individual is unable to make social security contributions while, for example, unemployed, sick, or on maternity leave, his or her contributions are in some circumstances credited by the state (contributi figurativi). The duration of these notional contributions depend on the occupation and on the reason why they are not made by the workers. ${ }^{2}$

The publicly-available database is extracted from the whole INPS database, and is based on a random sample of all individuals born on the first and the ninth day of each month of any year. It contains the complete contribution histories of all participants in the social security schemes administered by the INPS $^{3}$ (mainly employees in the private sector, employees in the public sector with fixed-term contracts, and self-employed individuals). The database contains information on each individual's employment, unemployment, and retirement spells from 1985 to 2014. Thus, for each year we are able to classify individuals as employed, unemployed, inactive, or retired based on the longest recorded spell. For instance, an individual who spent 5 months in employment, 3 months in unemployment, and 4 months in inactivity in a given year is classified as employed for that year. ${ }^{4}$ This means that any worker is considered employed if he/she pays contributions for the required amount of months during the study year. This is also the case of students who are part-time employees (collaboratori), of seasonal workers, of farmers, etc.

As the LoSaI sample is drawn from administrative registers, we distinguish between individuals who were unemployed or inactive depending on whether they were receiving unemployment benefits. We therefore define unemployment based on receipt of benefits and employment on contributions paid, an approach that is very common when using register-based administrative data. Our definitions are different from those used by many surveys, for instance those following ILO's guidelines, to define both employment and unemployment, and this should be taken into account when interpreting the results. As not all individuals looking for work meet the relatively strict eligibility requirements for unemployment benefits, and the coverage and the duration of these benefits are limited (Esser et al. 2013; OECD 2015a; Venn 2012), a sizable proportion of non-employed people are counted as inactive. For instance, workers with a contract that placed them in the legal category of self-employed (so-called parasubordinate workers) were not entitled to unemployment benefits, even if they were, in practice, in a dependent employment arrangement (Muehlberger and Pasqua 2009). The sample also includes information on each individual's demographic characteristics updated to 2014: i.e., date of birth, date of death, sex,

\footnotetext{
${ }^{2}$ More information is available at the INPS: https://www.inps.it/nuovoportaleinps/default.aspx?itemd ir $=46214$.

3 The database does not include information on either civil servants or freelance professionals.

4 Since 1996, the so-called "parasubordinati" workers have been included in the social security system through a fund called "Gestione Separata." These workers are legally self-employed, but often work as though they were employees. LoSaI classifies parasubordinati workers as either "professionals" or "collaborators." For professional parasubordinati, we have no information on employment spells, but we do have information on the contributions paid into the fund. For this reason, and because parasubordinati workers are often freelance professionals doing skilled work for clients, we classify these individuals as employed during the period of reference.
} 
Table 1 LoSaI sample, by sex, occupational category, and geographical area

\begin{tabular}{llr}
\hline & $\mathrm{N}$ & $\%$ \\
\hline Females & 322,454 & 36.3 \\
Males & 566,565 & 63.7 \\
Manager & 58,609 & 6.6 \\
Non-manual workers & 446,266 & 50.2 \\
Manual workers & 384,144 & 43.2 \\
North & 419,895 & 47.6 \\
Centre & 173,505 & 19.7 \\
South & 288,735 & 32.7 \\
\hline
\end{tabular}

Source: LoSaI 2003-2013; own calculations

and region of residence. The sample does not include information on individuals who are working "off the books".

Focusing on the years around the financial crisis, from 2003 to 2013, the final sample consists of more than 880,000 individuals for whom we are able observe at least a portion of the labor market trajectory. ${ }^{5}$ The main characteristics of our sample are summarized in Table 1. We consider three occupational categories: manual, non-manual, and professional workers (in managerial occupations). The information on the occupational category is obtained through the contributions paid by employers to occupational pension schemes. The occupational category is fixed; it does not change during one's working life. Categories are ranked from the lowest to the highest, that is: manual, non-manual, and managerial occupations. Individuals are classified according to the highest occupational category recorded during their working history. For example, an individual employed 3 years in manual occupations and 1 year in non-manual occupations will be assigned to the nonmanual occupational category. This classification refers to the pension fund (cassa) in which contributions are paid and position (qualifica). For instance, farmers (employees) are considered manual workers, collaborators working as self-employed are included in non-manual workers, while executives are in managerial occupations.

Almost $50 \%$ of the sampled individuals are employed in non-manual occupations and live in the northern regions of Italy, which are the most productive geographical areas of the country. Males are overrepresented, as female labor market participation has historically been low in Italy.

For individuals under age 65 with missing years in their contribution histories, we assume that they were out of the labor force during these years, and classify them as inactive. Missing years in contribution histories can be caused by two other main factors: i.e., individuals may have migrated abroad, or they may have been contributing to pension schemes not covered by the INPS. To account for the first possible factor, we adjust our calculations using the probability of out-migration, estimated on data provided by the National Institute of Statistics (ISTAT). In addressing the second possible factor, we note that the literature shows that the tendency to contribute to the same pension scheme over time is extremely strong, and that the likelihood that any contribution history gaps are attributable to switching to another fund is therefore negligible (Brugiavini and Brunello 1998).

\footnotetext{
${ }^{5}$ For around 1750 individuals, we have no information on the region of residence; thus, the individuals were excluded from the sample. As this group is rather small relative to the overall sample size, excluding them should not bias our results.
} 
Nevertheless, we apply a correction to our calculations and provide a sensitivity analysis to assess to what extent our estimates might be affected by the missing information.

\section{Methods}

\subsection{Estimation of WLE}

We estimate WLE using period working life tables. We specify a discrete-time Markov chain (Hoem 1977; Millimet et al. 2003), which models the year-to-year transitions of individuals between labor force states by means of transition probabilities. An alternative to the Markov chain approach is Sullivan's method. In contrast to the incidence-based Markov chain approach, it is prevalence-based. As we are interested in trends over time, incidencebased methods are preferred. Prevalence-based approaches yield biased results when there are abrupt changes in transition probabilities over time (Dudel et al. 2018; Mathers and Robine 1997), as surely was the case in Italy over the analysis period.

From age $15^{6}$ to age 99 , individuals can be in one of the following states: employed, unemployed, inactive, retired, or in the absorbing state dead. This means that the state space is given by the all of the pairs obtained as a combination of ages and states, and by the absorbing state dead. The state space is thus represented by elements categorized as "aged 15 and inactive", "aged 15 and employed", and so forth up to "aged 99 and retired", and "dead". As a consequence, individuals can move through transient states only in 1-year steps, for instance from "aged 25 and inactive" to "aged 26 and employed.

We assume that at age 99 no one in the sample is still alive, and that the individuals who are not in employment at ages 65 and older are retired. ${ }^{7}$ Individuals receiving a pension are considered employed if they have the required amount of contributions. Individuals older than 80 are all classified as retired since employment at older ages is quantitatively negligible.

Then, if $\mathrm{X}_{\mathrm{t}}$ is the labor force state at time $t$,

$$
P\left(X_{t+1}=\mathrm{i} \mid X_{t}=j\right)=p_{i j}
$$

is the transition probability from state $\mathrm{j}$ to the state $\mathrm{i}$ in a single time interval; in this case, 1 year. The transition probabilities regulate the movements of individuals across labor market states.

Individuals aged 15 begin inactive, and those who survive up to age 16 can stay inactive or move to any other transient state; the process continues at each successive age. At each age, transition probabilities sum up to the corresponding survival probability. For instance:

$$
\mathrm{p}(15, \mathrm{I})=\mathrm{p}(\mathrm{I} \mid 15, \mathrm{I})+\mathrm{p}(\mathrm{E} \mid 15, \mathrm{I})+\mathrm{p}(\mathrm{U} \mid 15, \mathrm{I})+\mathrm{p}(\mathrm{R} \mid 15, \mathrm{I})
$$

is the probability that an inactive individual aged 15 survives, in some year. That is, the survival probability is the sum of the probability of being inactive, or employed, or unemployed or retired at age 16, given that he/she was inactive at age 15; from age 15 to age 19

\footnotetext{
6 Starting September 2007, the legal minimum age for a person to work in Italy is 16 (Law 296/2006).

7 Since during the study period females employed in private sector could claim seniority pension at age 60 if they had accumulated at least 20 years of contributions, we used also a different specification of the state space to account for that. In this alternative scenario, females aged 60 and older, not in employment, are counted as retired. The two different specifications do not produce any noticeable difference in the resulting estimates. Table $\mathrm{C}$ in the appendix shows the results.
} 
there is a high persistence in the state inactive. This means that in this age group the inactive state nearly equals the survival probability.

To estimate the time spent in the different states using the Markov model, we calculate the fundamental matrix (Kemeny and Snell 1983; Taylor and Karlin 1998), with entries capturing WLE, time spent in retirement, and so on. To calculate this matrix, the transition probabilities are organized in the transition matrix $\mathrm{P}=\left[\mathrm{p}_{\mathrm{ij}}\right]$, separately for gender, region and occupation. As the state space includes all ages and movements are possible only in 1-year steps, the matrix $\mathrm{P}$ is a block diagonal matrix; off-diagonal blocks are zero matrices.

Using the transition matrix, the fundamental matrix is obtained by:

$$
\mathrm{N}=\left(\mathrm{I}_{\mathrm{s}}-\mathrm{U}\right)^{-1}
$$

where $I_{s}$ is an m-by-m identity matrix, and $U$ is an $m$-by-m matrix $(m=n-1$, number of states excluding the absorbing state dead). The superscript of -1 is used to denote the inverse. The entry of $\mathrm{N}$ in the $j$ th column and the $i$ th gives the expected time spent in state $i$ starting from state $j$. Given our model, this includes, for instance, the time spent in employment starting from the inactive state.

We provide estimates of the expected number of years spent in employment (WLE), unemployment, inactivity, and retirement from age 15 onward. This means, for instance, that our estimates of WLE show the years of life a 15-year-old can, on average, expect to spend in employment. The expected years of life spent in the different states sum up to remaining life expectancy. Furthermore, we decompose WLE by broad age groups (19 or younger; $20-29 ; 30-39 ; 40-49 ; 50-59 ; 60$ and older). This allows us to assess how changes in WLE are distributed across age groups, and whether specific groups, such as older or younger individuals, experienced greater changes in WLE than other groups.

\subsection{Transition Probabilities}

We estimate the transition probabilities by means of multinomial regressions (Agresti 2003; Allison 1982). We model the probability of being in state $i$ at time $t+1$ as a function of the state $j$ at time $t$, age, sex, occupational category, and macro area ${ }^{8}$ of residence. Moreover, as the data used in the analysis span the years 2003-2013, a dummy variable for each period from 2004 to 2012 is included in the models to control for trend; 2003 is used as reference period, while 2013 is not included, as we model transitions from $t$ to $t+1$. In each of the regressions, age is modelled as a cubic spline to account for non-linearity in the relationship between age and the probability of being in a state $i$.

The sample size allows us to estimate regression models separately by gender and age groups, as well as by occupational category and by macro area of residence. This approach introduces implicit interactions between the variables that were used to split the data, and helps to ensure that the computations remain feasible, which would otherwise be very time intensive. The age groups considered are those chosen to decompose WLE; that is, from 15 to 29 , from 30 to 64 and from 65 to 99 . These groups roughly reproduce ages at entry into the labor market, working ages, retirement ages and end of life.

Estimating the transition probabilities as described above yields estimates for transitions from $t=2003$ to $t+1=2004, t=2004$ to $t+1=2005$, and so on. Each of these sets

\footnotetext{
${ }^{8}$ Macro areas are defined according the nomenclature of territorial units for statistics NUTS. From the NUTS 1 level, we combine the North-East with the North-West in the North category, and the South with the Islands in the South category.
} 
of transition probabilities is plugged into the Markov chain approach to derive estimates of WLE. This means that, for instance, the transitions from 2003 to 2004 are used to derive an estimate of WLE for the same period. The result follows a so-called period perspective, which is commonly used for WLE (e.g., Hayward and Lichter 1998). It shows how long the length of working life of a hypothetical cohort would be if the conditions captured by the transitions from $t$ to $t+1$ prevailed over a life time. Thus, period WLE provides a summary of the labor market, and the time series of estimates that we calculate in this paper allow us to assess how the labor market changes over time. The other measures we provide in this paper, such as the years of life spent in retirement, also follow a period perspective.

We classify the years in which the employment rate was declining and the unemployment rate was increasing as periods of recession. It is important to note, however, that this definition of recession differs from the definition of recession commonly used in economics: i.e., two consecutive quarters of negative economic growth. Labor Force Statistics (ISTAT 2017) show that in Italy, the decreasing trend in the total employment rate started after the second quarter of 2008. Following a period of stability between 2010 and 2011 , the decreasing trend resumed starting with the second quarter of 2012, and continued until the end of the period covered by our data (2013). This implies that in our analysis, the beginning of the recession is covered by the three 2-year periods of 2007-2008, 2008-2009, and 2009-2010.

All of the analyses were performed by means of the statistical language $\mathrm{R}$ ( $\mathrm{R}$ Core Team 2016). We used the package readr (Wickham et al. 2016) to import the raw data, data.table (Dowle and Srinivasan 2017) for data management, VGAM (Yee 2010) to estimate the multinomial models, and ggplot2 (Wickham 2009) to create the figures.

\subsection{Adjustments of Transition Probabilities}

Since the sample is based on register data, it collects information on individuals with contribution histories in the occupational pension schemes covered by INPS. This approach has two major implications that need to be addressed. First, the sample includes only individuals with at least one contribution record. This means that individuals who have never worked or who made contributions to funds not covered by the sample are not included in the data. Second, individuals previously included in the sample are lost to the follow-up if they either moved abroad or started contributing to funds not covered by the data. We address these problems in the following way.

First, including only individuals with contribution records implies that the transition probability estimates from inactivity to employment are likely to be biased upward. Furthermore, it is reasonable to assume that especially as individuals grow older, those who already have work experience are more likely than those who do not to transition from inactivity to employment. This problem does not affect the estimates for all other states, such as from unemployment to employment or from employment to retirement. Thus, we address this issue by estimating the transition probabilities from inactivity to employment by means of a nonparametric approach. We use the LoSaI sample to estimate the transitions from inactivity to employment by age and sex, weighting our observations by the inverse of the inclusion probability in the sample, 365:24. Then, we estimate the whole inactive population, by age and sex, by means of the publicly available data of the Italian Institute of Statistics (ISTAT), "Aspects of daily life". The resulting estimate of the inactive population may be assumed to be the correct number of individuals who have the potential to transition from inactivity to other states. 
A second adjustment is applied to the survival probabilities resulting from the multinomial models. This adjustment is needed because the survival probabilities estimated within the regression models can result in unrealistically high life expectancies. We use the life tables provided by ISTAT at both the whole population and the macro area levels to replace the parametric survival estimates with adjusted estimates. These are obtained by decomposing the survival probabilities provided in the life tables according to the survival distribution by occupational status observed in the sample. The detailed procedure is described in Dudel and Myrskylä (2017).

\section{Results}

Our findings are based on Multistate Period Life Tables and must be interpreted accordingly. That is, the following results refer to a synthetic cohort of individuals who experience throughout their lives both the mortality and labor market conditions prevalent in a specific period. This makes the concept of WLE parallel to the better known concept of life expectancy, and thus WLE represents the expected number of years in employment for an individual aged 15 .

We present the results of aggregating the expected years of inactivity and the expected years of unemployment, as the estimated years of unemployment are very small as a consequence of our definition of unemployment; detailed disaggregated tables are provided in Appendix B.

\subsection{Trends in WLE by Gender}

In 2003-2004, the WLE of men was 35.2 years and the WLE of women was 34.7 years (Table 2). For both men and women, WLE was quite stable until 2006-2007. But in 2007-2008, WLE declined by 1.6 years among men and by 4.3 years among women. Much greater losses occurred in the subsequent period, when WLE decreased by more than 3 years for men and by more than 4 years for women. WLE bounced back slightly in the 2009-2010 period, but reached the lowest levels observed since the onset of the recession in the 2012-2013 period.

The economic recession affected male and female employment differently: from 2006-2007 to 2012-2013, the loss in WLE was about 8 years for men and 11 years for women. The expected number of years in inactivity followed the opposite trend, and by the end of the study period, the number of years of inactivity had doubled for both men and women: i.e., from 8.4 to 17.9 years for men and from 11.8 to 22.0 years for women. The increase in inactivity mirrors the growth in unemployment, so we aggregated them; detailed disaggregated tables are provided in Appendix B.

The duration of retirement and its trend are very relevant for assessing the financial viability of the pension system, and for formulating any policy aiming at extending working lives. This measure was hardly affected by the economic crisis: between 2007 and 2013, the expected number of years spent in retirement has been consistently around 20 years for men and around 25 years for women (Fig. 1). Over the 10-year study period, total life expectancy increased about 2.4 years for males and 1.6 years for females. Thus, WLE as fraction of total life expectancy would have declined if it had not increased in proportion to the gains in life expectancy. Between 2003 and 2012, the decline of WLE as fraction of total life expectancy for both men and women was consistently larger than the increase in 
Table 2 Life expectancy (in years) at age 15 spent in employment, unemployment, and retirement, by sex-Italy, 2003-2013

\begin{tabular}{|c|c|c|c|c|}
\hline & Employed & Inactive & Retired & Total \\
\hline \multicolumn{5}{|l|}{ Males } \\
\hline $2003 / 2004$ & 35.2 & 8.4 & 19.1 & 62.7 \\
\hline $2004 / 2005$ & 34.9 & 9.1 & 19.4 & 63.5 \\
\hline $2005 / 2006$ & 34.8 & 9.0 & 19.7 & 63.6 \\
\hline $2006 / 2007$ & 35.2 & 9.2 & 19.6 & 64.0 \\
\hline $2007 / 2008$ & 33.6 & 10.3 & 20.2 & 64.1 \\
\hline $2008 / 2009$ & 30.2 & 13.7 & 20.3 & 64.1 \\
\hline $2009 / 2010$ & 30.0 & 14.7 & 19.8 & 64.5 \\
\hline $2010 / 2011$ & 30.4 & 14.4 & 20.0 & 64.9 \\
\hline $2011 / 2012$ & 28.6 & 16.6 & 19.8 & 65.0 \\
\hline $2012 / 2013$ & 27.2 & 17.9 & 20.0 & 65.1 \\
\hline \multicolumn{5}{|l|}{ Females } \\
\hline $2003 / 2004$ & 34.7 & 11.8 & 21.7 & 68.2 \\
\hline $2004 / 2005$ & 33.0 & 13.2 & 22.9 & 69.1 \\
\hline $2005 / 2006$ & 32.7 & 12.7 & 23.6 & 69.0 \\
\hline $2006 / 2007$ & 33.6 & 11.9 & 23.9 & 69.3 \\
\hline $2007 / 2008$ & 29.2 & 15.6 & 24.6 & 69.3 \\
\hline $2008 / 2009$ & 25.1 & 19.5 & 24.7 & 69.3 \\
\hline $2009 / 2010$ & 26.1 & 18.6 & 24.7 & 69.5 \\
\hline $2010 / 2011$ & 26.7 & 18.3 & 24.7 & 69.8 \\
\hline $2011 / 2012$ & 25.9 & 19.0 & 24.8 & 69.8 \\
\hline $2012 / 2013$ & 23.7 & 22.0 & 24.0 & 69.7 \\
\hline
\end{tabular}

Source: LoSaI 2003-2013; own calculations

life expectancy; Fig. 1 shows the pattern of WLE as a fraction of the total life expectancy. For men, there has been a nearly continuous declining trend since 2006/2007; and the overall level of $40 \%$ in the latest data point is quite low. For women, the $34 \%$ figure seems very low: starting from age 15 , the average woman works only every third year for the rest of her life.

Our results show that during the study period, the number of life years gained by both males and females were mostly distributed in years of inactivity due to the circumstances created by the economic crisis. However, the fraction of years spent in retirement was stable or slightly decreasing as a result of pension system reforms.

\subsection{Occupational Differences}

Figure 2 shows WLE by occupational categories providing a picture of how selectively the economic crisis hit various groups of workers. During the recession period the existing differences by occupational group widened.

For men, in 2003-2004, the expected number of years in employment ranged from 34.3 for manual workers to 42.7 for individuals employed in managerial occupations. The difference is even more striking for women, among whom the expected number of years in employment ranged from 32 for manual workers to more than 42 for those employed in managerial occupations. WLE was stable until 2006/2007 when it started to decline during 


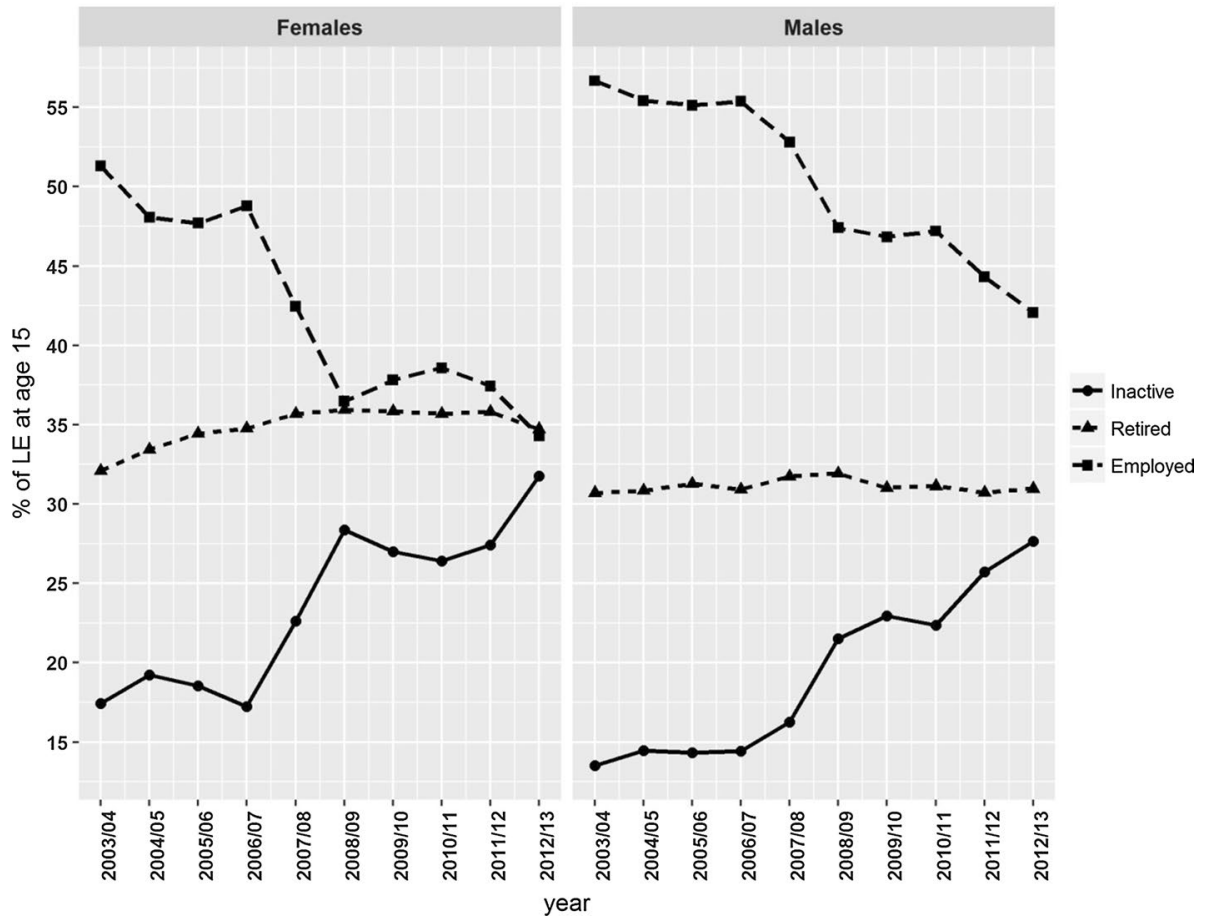

Fig. 1 Fraction of life expectancy at age 15 spent in employment, inactivity, and retirement, by sex. Source: LoSaI 2003-2013; own calculations

the economic crisis. In 2012/2013, the number of expected years spent in employment decreased by about eight for male manual workers and about six for non-manual workers and managers. The decline in the number of years spent in employment again appears to have been more dramatic for women, with women in manual non-manual and managerial jobs losing about 10 years. Overall, from the beginning of the crisis, the gender gap increased across all occupations.

\subsection{Regional Disparities}

There is a strong longstanding North-South gradient in the Italian labor market (Lagravinese 2015; Reyneri 2002). According to the Italian statistical office (ISTAT), the employment rate in 2015 was $49.0 \%$ in the North, $46.7 \%$ in the Center, and $33.3 \%$ in the South. These large regional disparities are reflected in our WLE results by sex and area, as shown in Fig. 3. In 2003/2004, the expected number of years spent in employment was more than 36 years for males living in both the Northern and the Central regions of Italy, but was only 33.8 years for males living in the South. Among women, similar differences can be observed: the WLE was 36 years in the North and in the Center, and 32.9 years in the South. Until 2006/2007, WLE was stable for both males and females, irrespective of the area of residence. But following the onset of the financial crisis, WLE dropped considerably in all areas and for both sexes. The magnitude of the observed decline followed the 


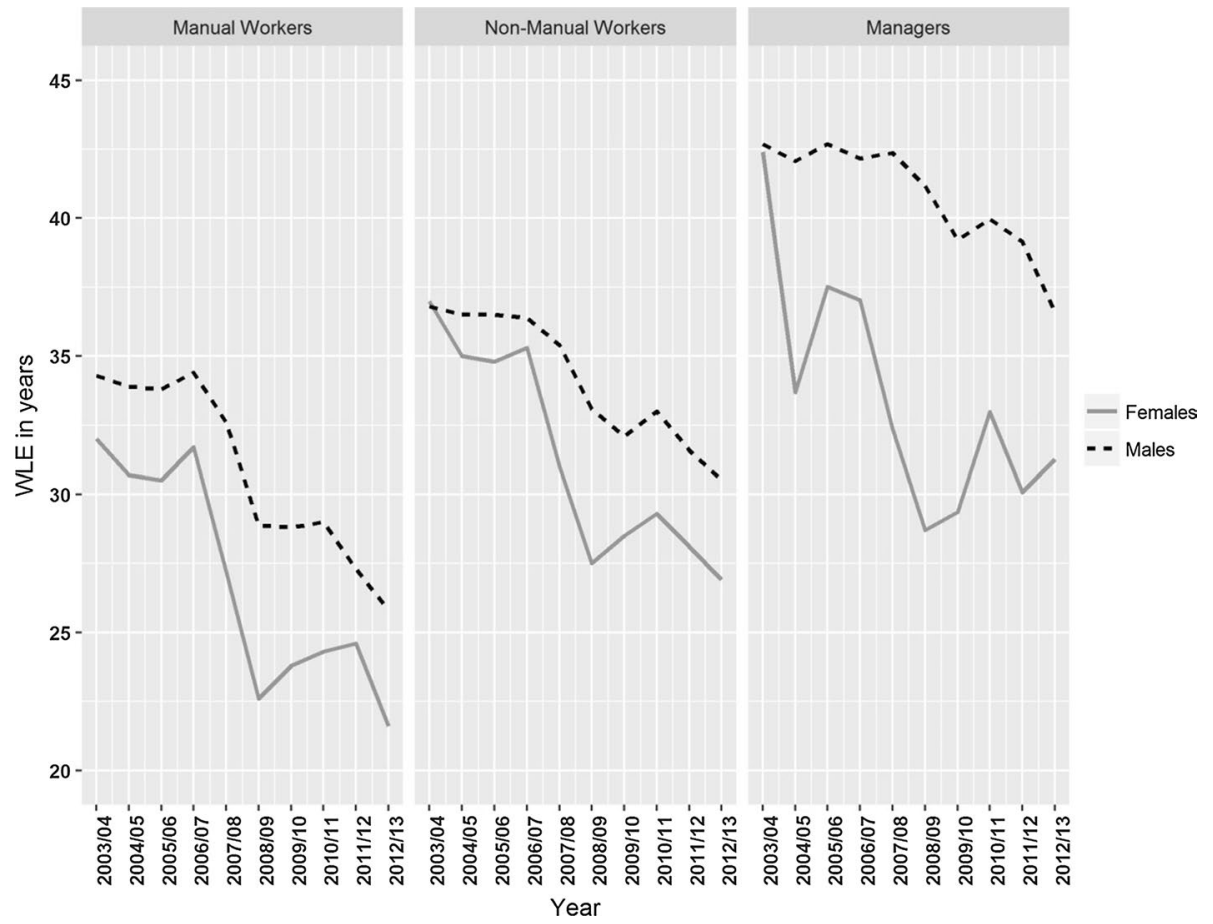

Fig. 2 Working life expectancy by occupational category and sex-Italy, 2003-2013. Source: LoSaI 20032013; own calculations

North-South gradient, but the trend was nearly the same. At the end of the period, the North-South gap in WLE was 4.4 years for males and 4.6 years for female.

\subsection{Decomposition by Age Groups}

The previous results show that the crisis hit both men and women, but that women appear more vulnerable. The increased participation of women in the labor market is a relatively recent phenomenon in Italy, and is particularly relevant for younger women (Scherer and Reyneri 2008). Thus, to better understand the impact of the crisis on WLE, we provide a measure of change in WLE between 2006/2007 and 2009/2010 by age groups and sex. The number of working years lost between 2006/07 and 2009/2010 was about five for males and almost seven for females. Men and women show similar patterns by age, with younger individuals being the most severely affected by the crisis (Fig. 4). Among individuals aged 60 and older, the loss was minor for males, at about 0.4 years. The change seems larger in the case of women, but it is still small. The increase in inactivity for females aged 60 and older is also very limited. Figure 4 also shows a large difference between the age groups 50-59 and 60 and older, which is likely a consequence of early retirement. That is, at ages $60+$ a large share of individuals were already retired; therefore, this group contributes only marginally to the change in WLE. For individuals aged 30-39, 40-49, and 50-59, the average loss was less than 1 year for males and more than 1.2 years for females. The greatest decline in WLE was for individuals aged 20-29: males lost 1.7 years and females lost 


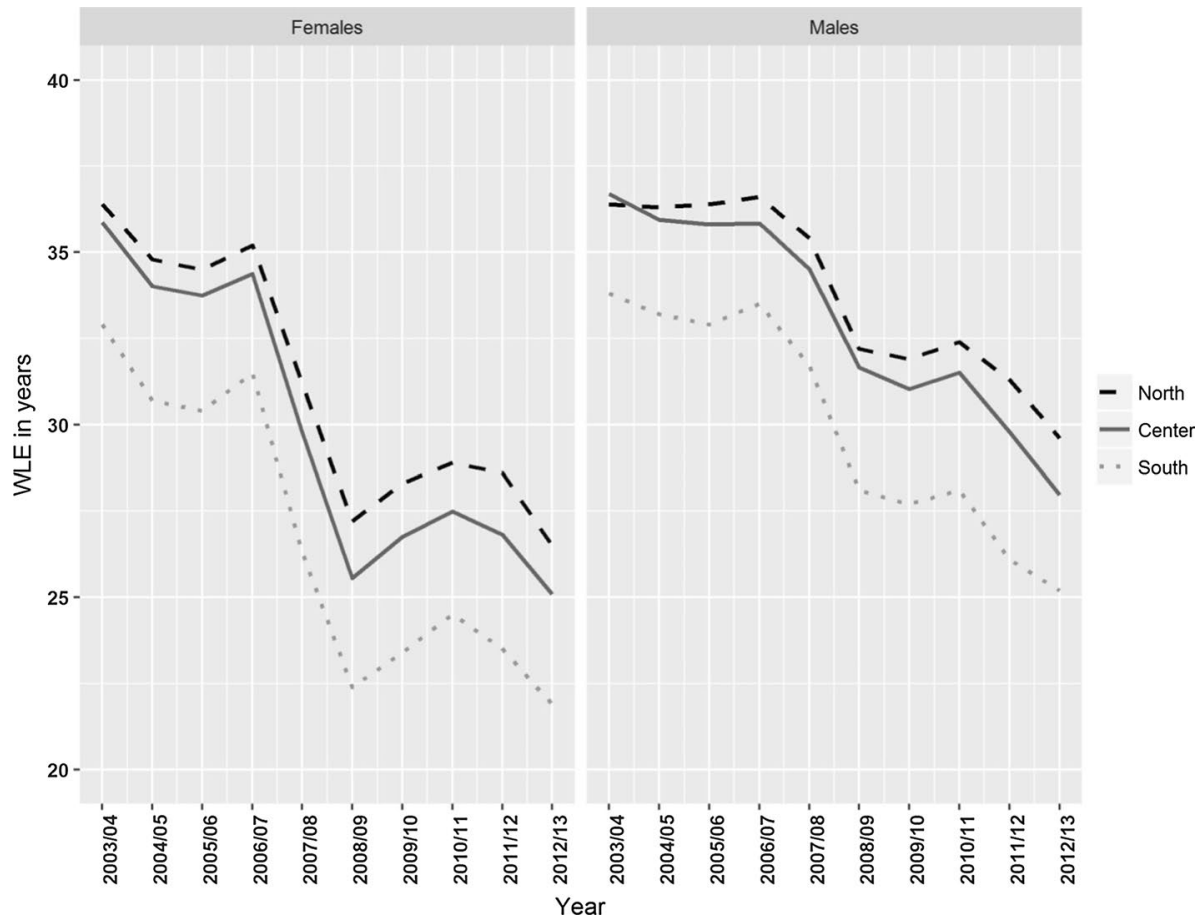

Fig. 3 Working life expectancy by geographic area and sex-Italy, 2003-2013. Source: LoSaI 2003-2013; own calculations

2.4 years. These numbers are especially striking given that younger ages contribute less than older ages to the total WLE. The difference between the sexes at the youngest ages $(<19)$ might be due to low participation; thus, the contribution of this age group to the WLE loss is marginal.

\section{Discussion}

\subsection{Main Findings}

In this study we estimated for the first time the length of working life in Italy considering the full life cycle from age 15 onwards. Before the onset of the recession the expected number of years in employment was about 35 for men and about 33 for women. Thus, starting from age 15 , the average individual was expected to spend about $55 \%$ of his remaining life in employment if male, and $48 \%$ if female. The decline in working life expectancy that occurred during the years of the crisis was huge: from 2003-2004 to 2012-2013 men lost about 8 years of working life expectancy and women 11 years. The fraction of remaining life at age 15 expected in employment fell down to 42 and $34 \%$ for men and women respectively. As a consequence, in 2012-2013, remaining life expectancy in employment of women was equal to remaining life expectancy in retirement. 


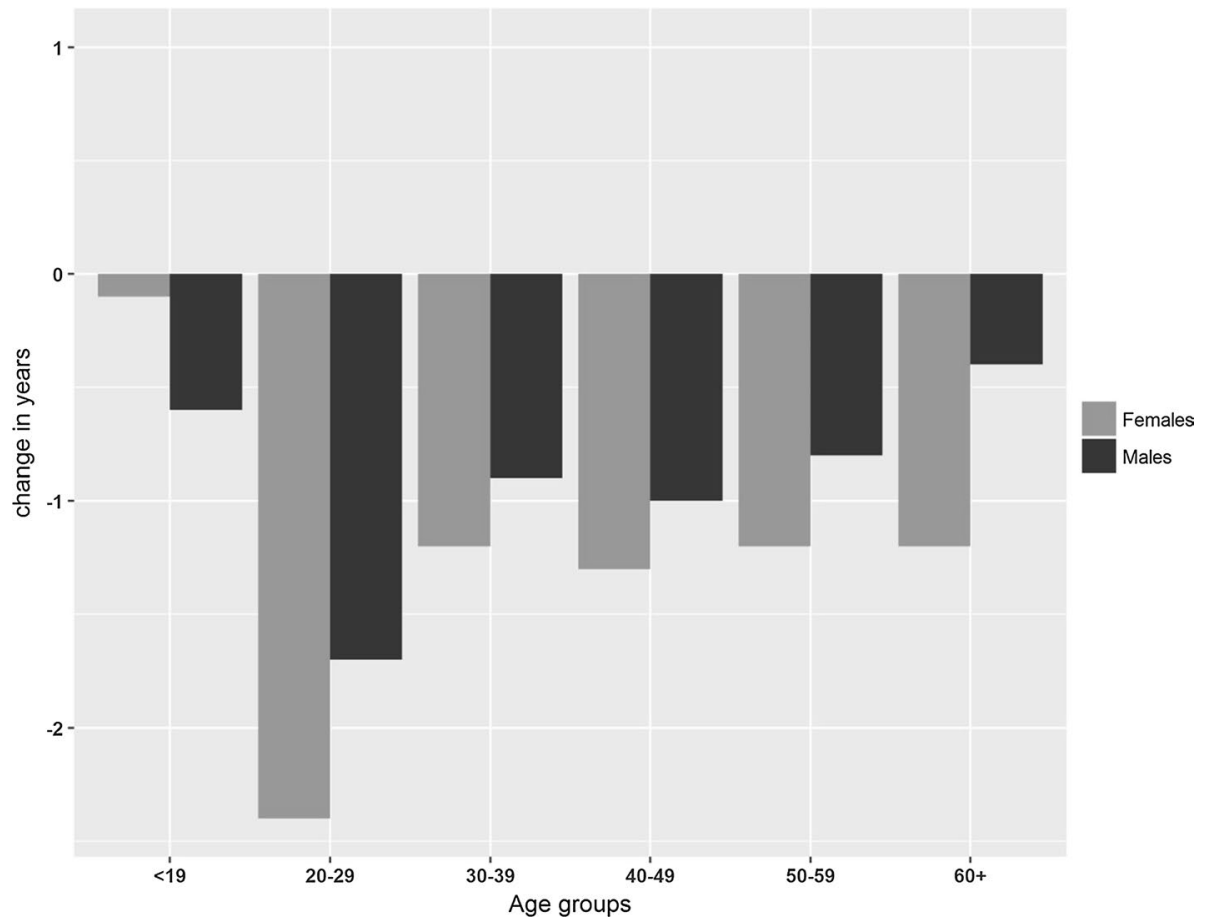

Fig. 4 Decomposition of the change in WLE between 2006/2007 and 2009/2010 by age groups and sex. Source: LoSaI 2003-2013; own calculations

Our results highlight the employment vulnerability of Italian women to the harshness of the crisis. The decreases in WLE between 2003-2004 and 2012-2013 were of 32\% for women, $9 \%$ larger than for man. As a result, the gap between males and females rose from 0.5 to 3.5 years. The greater vulnerability might be attributable to their disproportionate levels of temporary and flexible employment (Barbieri and Scherer 2009; Scherer and Reyneri 2008). Women who were employed under a fixed-term contract had very low probability of moving from temporary to permanent employment (ISTAT 2013). Most such contracts are short in duration, and, until recently, there was no requirement that they provide unemployment insurance. The duration and the coverage of unemployment benefits were limited, and unemployment insurance was partial and highly fragmented (e.g. Barbieri and Scherer 2009). Consequently, the increase in unemployment following the crisis translated into an increase in inactivity. Looking at the trend, from 2003-2004 to 2012-2013 inactivity doubled, from 8.4 to 17.9 years for men and from 11.8 to 22.0 years for women.

We also found a strong decline in working life expectancy across all occupational categories; however, the impact was greatest for those in lower skilled (manual) occupations. Over the 10-year period WLE for men in manual occupations declined by about 25 and $33 \%$ for women. These findings are consistent with the results of the international literature on the crisis, as well as with the findings of previous studies on WLE (Leinonen et al. 2015; Millimet et al. 2003) and particularly with more recent findings on Spain (Dudel et al. 2018). The international literature also suggests that highly skilled workers retire later than less skilled workers (Blöndal and Scarpetta 1997; Ebbinghaus 2006). 
Our results at the (macro) regional level-North, Center, South-reflect the well-known North-South economic gradient. In 2003-2004 working life expectancy for both men and women was about 36 years in the northern and central regions, while about 34 for men and 33 years for women residing in the South. The economic downturn appears to have widened the existing gap, and the resulting difference is striking: in 2012-2013, the gap in working life expectancy between men living in the North and women living in the South was approximately 8 years. This is the first study to our knowledge to estimate working life expectancy at the regional level. Our results are in line with previous findings on the effects of the crisis and regional disparities (O'Higgins 2011).

There was evidence of a negative age gradient from the age distribution of years of employment lost for both men and women. The younger the individuals were, the higher the number of years of employment lost. During the study period the decreases in WLE for individuals of age 20-29 were about 35 and $31 \%$ for men and women, respectively, whereas at ages $50-59$, they were about $10 \%$ for men and $24 \%$ for women.

Working life expectancy in Italy is low by international comparison. Before the beginning of the crisis (2005-2006), WLE at age 15 for males was shorter in Italy than in Spain while longer for females (Dudel et al. 2018). Although the overall level of WLE at the end of the period is slightly higher for Spain, the evolution of WLE during the recession appears to have been quite similar in the two countries. The roots of these differences in WLE might be traceable to the very low employment rates at younger ages in Italy, and from ages 30-39 onwards they gradually disappear. The estimates of WLE at age 50 in Finland (see Leinonen et al. 2015) are also very close to the estimates for Italy. In contrast, there are much larger differences in WLE at older ages between Italy and the U.S (Dudel and Myrskylä 2017). In the U.S., it is not uncommon to return to work after retirement (Cahill et al. 2006; Giandrea et al. 2009; Hardy 1991; Hayward et al. 1994); while in Italy, combining income from work and pension benefits was not possible until 2009.

\subsection{Methodological Considerations}

The analytical framework we used to estimate WLE is based on a period perspective. Consequently, our results must be interpreted as reflecting those of a synthetic cohort of individuals who experienced both the mortality and the labor market conditions of a specific period throughout their lives. Bearing this in mind when interpreting the results (also see Leinonen et al. 2015), our estimates provide a ready snapshot of the phenomenon under study, and enable us to assess the full impact of the Great Recession. While our study data allowed us to differentiate according to gender, occupation, and area of residence, there are other dimensions that might have been relevant, but that we could not investigate because our data did not include this information. For example, while there is evidence that the economic crisis affected migrants more than natives in Italy (Bonifazi and Marini 2014), we were unable to distinguish between migrants and non-migrants. Nevertheless, the decline in WLE reflects the changes in labor force measures (e.g., employment, unemployment, and inactivity rates) observed during the crisis period, leading us to believe that our results can be attributed to the downturn.

Our estimated WLE only captured the time spent in employment, irrespective of whether it was in full-time or part-time work. We also could not capture short spells of work, which were prevalent in the years of the crisis (Aricò and Stein 2012). Defining the employment status on the basis of annual spells has certain implications. For instance, individuals who worked only 3 months at the end of year $t$ and 5 months at the beginning of year $t+1$ were classified as unemployed or inactive in both years $t$ and $t+1$. Therefore, 
we lost 8 months of employment during the period between $t$ and $t+1$. One way to overcome this problem is to use a finer classification based on monthly employment states. Although technically feasible, this strategy introduces other problems; most importantly, it would have prevented us from applying any corrections on survival, migration, and selection that were based on data available on an annual basis only. However, as we expect that short spells contributed relatively little to the overall proportions of life spent in any given state, we believe that the failure to capture short spells of work did not introduce significant bias (also see Dudel et al. 2018).

\section{Conclusions}

In this paper, we provided for the first time a picture of the length of working life in Italy, and estimates of working life expectancy at a regional level. Exploiting rich social security register data on individual occupational episodes and mortality events, we estimated working life expectancy (WLE); i.e., the expected years of life spent in employment. We described how WLE has evolved in recent years, and also provided estimates of the years of life spent in retirement and inactivity. Our findings show that during the recent financial crisis the gender gap in WLE increased, and the difference between men and women, in 2012-2013, was 3.5 years. Differences were also found across occupational categories: in 2012-2013, WLE of individuals in manual occupations was about 30\% shorter than the WLE of those in managerial occupations. Over the study period the existing regional disparities were exacerbated; the WLE of individuals in the North was about 4.5 years larger for both men and women than in the South of Italy. The effects of the crisis were particularly severe for younger workers, for men about $40 \%$ of the decline in WLE, between 2003 and 2013, was attributable to ages below 30, and for women about $24 \%$.

Our findings could be considered rather disturbing, as discontinued careers and the limited accumulation of contributions may result in inadequate pension benefits later in life. This issue is particularly relevant since the implementation of the Fornero reform law, which transformed the pension scheme into a DC plan. Thus, the benefit amounts future retirees receive will be heavily dependent on the accumulation of contributions made over their working careers. Moreover, episodes of unemployment might have scarring effects and long-run negative effects on labor market integration (Bell and Blanchflower 2011). This appears to be a significant problem, especially when considered in concert with the spread of atypical employment contracts, which has negatively affected the likelihood of finding stable employment (Barbieri and Scherer 2009). If these issues are not properly addressed, youth unemployment could turn into a major social problem.

Working life expectancy and related indicators are rich sources of information for policy-makers who face challenges associated with population aging, including the question of how the financial viability of the social security system can be guaranteed. This issue is certainly relevant for Italy, which not only has one of the oldest populations in the world, but a huge public debt and a rigid labor market. Our results show that working life expectancy is heterogeneous. It is crucial for Italy to not only extend the average working life by raising the age at retirement, but also to seek to increase employment levels at all ages, particularly among women, young people, and people who live in the South.

Acknowledgements Open access funding provided by Max Planck Society. 
Open Access This article is distributed under the terms of the Creative Commons Attribution 4.0 International License (http://creativecommons.org/licenses/by/4.0/), which permits unrestricted use, distribution, and reproduction in any medium, provided you give appropriate credit to the original author(s) and the source, provide a link to the Creative Commons license, and indicate if changes were made.

\section{References}

Agresti, A. (2003). Categorical data analysis. Wiley. Retrieved https://books.google.de/books ?id=hpEzw4T0sPUC.

Allison, P. D. (1982). Discrete-time methods for the analysis of event histories. Sociological Methodology, 13, 61-98.

Aricò, F. R., \& Stein, U. (2012). Was short-time work a miracle cure during the great recession? The case of Germany and Italy. Comparative Economic Studies, 54(2), 275-297.

Arpaia, A., Curci, N., \& Economic and Financial Affairs. (2010). EU labour market behaviour during the great recession. Brussels: European Commission.

Barbieri, P., Cutuli, G., Luijkx, R., Mari, G., \& Scherer, S. (2016). Substitution, entrapment, and inefficiency? Cohort inequalities in a two-tier labour market. Socio-Economic Review, mww035. https ://doi.org/10.1093/ser/mww035.

Barbieri, P., \& Scherer, S. (2009). Labour market flexibilization and its consequences in Italy. European Sociological Review, 25(6), 677-692.

Bell, D. N. F., \& Blanchflower, D. G. (2011). Young people and the great recession. Oxford Review of Economic Policy, 27(2), 241-267.

Billari, F. C., \& Rosina, A. (2004). Italian 'latest-Late' transition to adulthood: An exploration of its consequences on fertility. Genus, 60(1), 71-87. http://www.jstor.org/stable/29788793.

Billari, F. C., \& Tabellini, G. (2010). Italians are late: Does it matter? pp. 371-412 in demography and the economy. Chicago: University of Chicago Press.

Blöndal, S., \& Scarpetta, S. (1997). Early retirement in OECD countries: The role of social security systems. OECD Economic Studies, 29, 7-54.

Bonifazi, C., \& Marini, C. (2014). The impact of the economic crisis on foreigners in the Italian labour market. Journal of Ethnic and Migration Studies, 40(3), 493-511.

Bono, F., Cracolici, M. F., \& Cuffaro, M. (2016). A hierarchical model for analysing consumption patterns in Italy before and during the great recession. Social Indicators Research. https://doi. org/10.1007/s11205-016-1441-z.

Brugiavini, A. (2001). Early retirement in Europe. European Review, 9(4), 501-515.

Brugiavini, A., \& Brunello, G. (1998). An empirical analysis of interfirm mobility in Italy. Giornale Degli Economisti E Annali Di Economia 57(Anno 1(1)), 1-34. Retrieved http://www.jstor.org/stabl e/23248161.

Butt, Z., Haberman, S., Verrall, R., \& Wass, V. (2008). Calculating compensation for loss of future earnings: Estimating and using work life expectancy. Journal of the Royal Statistical Society Series a-Statistics in Society, 171, 763-800.

Butt, Z., Haberman, S., Verrall, R., \& Wass, V. (2010). Work life expectancy: Calculating compensation for loss of future earnings. Measurement \& Control, 43(5), 146-151.

Cahill, K. E., Giandrea, M. D., \& Quinn, J. F. (2006). Are traditional retirements a thing of the past? New evidence on retirement patterns and bridge jobs. Business Perspectives, 18(2), 26.

Cirillo, V., Fana, M., \& Guarascio, D. (2017). Labour market reforms in Italy: Evaluating the effects of the jobs act. Economia Politica. https://doi.org/10.1007/s40888-017-0058-2.

D'Ambrosio, C., \& Rohde, N. (2014). The distribution of economic insecurity: Italy and the U. S. over the great recession. Review of Income and Wealth, 60, S33-S52.

Dowle, M., \& Srinivasan, A. (2017). Data.table: Extension of 'data.frame'. Retrieved https://cran.r-proje ct.org/package $=$ data.table.

Dudel, C., Gómez, M. A. L., Benavides, F. G., \& Myrskylä, M. (2018). The length of working life in Spain: Levels, recent trends, and the impact of the financial crisis. European Journal of Population. https://doi.org/10.1007/s10680-017-9458-9.

Dudel, C., \& Myrskylä, M. (2017). Working life expectancy at age 50 in the United States and the impact of the great recession. Demography, 54(6), 2101-2123. https://doi.org/10.1007/s1352 4-017-0619-6.

Ebbinghaus, B. (2006). Reforming early retirement in Europe. Oxford: Oxford University Press. 
Esser, I., Ferrarini, T., Nelson, K., Palme, J., \& Sjöberg, O. (2013). Unemployment benefits in EU member states. Paris: European Commission, Directorate-General for Employment, Social Affairs and Inclusion.

Eurostat. (2017a). Population on 1 January by age and sex. Retrieved January 9, 2017. http://appss o.eurostat.ec.europa.eu/.

Eurostat. (2017b). Unemployment by sex and age - quarterly average. Retrieved (Online DB).

Giandrea, M. D., Cahill, K. E., \& Quinn, J. F. (2009). Bridge jobs a comparison across cohorts. Research on Aging, 31(5), 549-576.

Haberman, S., \& Bloomfield, D. S. F. (1990). Work time lost to sickness, unemployment and stoppages: Measurement and application. Journal of the Institute of Actuaries (1886-1994) 117(3), 533-595. Retrieved http://www.jstor.org/stable/41140988.

Hardy, M. A. (1991). Employment after retirement who gets back in? Research on Aging, 13(3), 267-288.

Hayward, M. D., \& Grady, W. R. (1990). Work and retirement among a cohort of older men in the United-States, 1966-1983. Demography, 27(3), 337-356.

Hayward, M. D., Hardy, M. A., \& Liu, M. C. (1994). Work after retirement-the experiences of older men in the United-States. Social Science Research, 23(1), 82-107.

Hayward, M. D., \& Lichter, D. T. (1998). A life cycle model of labor force inequality: Extending Clogg's life table approach. Sociological Methods \& Research, 26(4), 487-510. https://doi. org/10.1177/0049124198026004003).

Hoem, J. M. (1977). A Markov chain model of working life tables. Scandinavian Actuarial Journal, 1977(1), 1-20. https://doi.org/10.1080/03461238.1977.10405621.

ISTAT. (2013). Rapporto Annuale 2013 - La Situazione Del Paese.

ISTAT. (2017). Labour force statistics. Retrieved http://dati.istat.it/.

Keeley, Brian, \& Love, Patrick. (2010). OECD insights from crisis to recovery the causes, course and consequences of the great recession: The causes, course and consequences of the great recession. Paris: OECD Publishing.

Kemeny, J. G., \& Snell, J. L. (1983). Finite Markov chains: with a new appendix "generalization of a fundamental matrix.” Springer, New York. Retrieved https://books.google.de/books?id=0bTK5uWzbYwC.

Lagravinese, R. (2015). Economic crisis and rising gaps north-south: Evidence from the Italian Regions. Cambridge Journal of Regions Economy and Society, 8(2), 331-342.

Leinonen, T., Martikainen, P., \& Myrskylä, M. (2015). Working life and retirement expectancies at age 50 by social class: Period and cohort trends and projections for Finland. The Journals of Gerontology Series B, 73(2), 302-313. https://doi.org/10.1093/geronb/gbv104.

Liefbroer, A. C., Liefbroer, A. C., \& Henkens, K. (1999). Labour market careers of successive cohorts of older men in the Netherlands: Changes in age at retirement and in length of working lives. Genus, 55, 101-119. http://www.jstor.org/stable/29788592.

Loichinger, E., \& Weber, D. (2016). Trends in working life expectancy in Europe. Journal of Aging and Health, 28(7), 1194-1213.

Mathers, C. D., \& Robine, J. M. (1997). How good is Sullivan's Method for monitoring changes in population health expectancies. Journal of Epidemiology and Community Health, 51(1), 80-86.

Millimet, D. L., Nieswiadomy, M., Ryu, H., \& Slottje, D. (2003). Estimating worklife expectancy: An econometric approach. Journal of Econometrics, 113(1), 83-113.

Muehlberger, U., \& Pasqua, S. (2009). Workers on the border between employment and self-employment. Review of Social Economy, 67(2), 201-228.

Mussida, C., \& Sciulli, D. (2016). The trend over time of labour market opportunities for young people in Italy. Economia Politica, 33(2), 291-321. https://doi.org/10.1007/s40888-016-0028-0).

Nurminen, M. M., Heathcote, C. R., Davis, B. A., \& Puza, B. D. (2005). Working life expectancies: The case of Finland 1980-2006. Journal of the Royal Statistical Society Series a-Statistics in Society, $168,567-581$.

O'Higgins, N. (2011). Italy: Limited policy responses and industrial relations in flux, leading to aggravated inequalities. In Work inequalities in the crisis: Evidence from Europe 314-49.

O'Higgins, Niall. (2012). This time it's different? Youth labour markets during 'the Great Recession'. Comparative Economic Studies, 54(2), 395-412.

OECD. (2013). Pensions at a Glance 2013: OECD and G20 indicators. Paris: OECD Publishing.

OECD. (2015a). OECD economic surveys: Italy 2015. OECD Publishing. Retrieved https://books.googl e.de/books?id=cRS9BgAAQBAJ.

OECD. (2015b). Pensions at a Glance 2015: OECD and G20 indicators. Paris: OECD Publishing.

OECD. (2017). Quarterly national accounts: Quarterly growth rates of real GDP, Change over previous quarter. Retrieved http://stats.oecd.org/Index.aspx?QueryName=350\&QueryType=View\&Lang=en\#. 
R Core Team. (2016). R: A Language and Environment for Statistical Computing. Retrieved https:// www.r-project.org/.

Reyneri, E. (2002). Sociologia Del Mercato Del Lavoro. Il Mulino. Retrieved https://books.google.de/ books?id=UpxXAAAAYAAJ.

Sarti, S., \& Zella, S. (2016). Changes in the labour market and health inequalities during the years of the recent economic downturn in Italy. Social Science Research, 57, 116-132.

Scherer, S. (2005). Patterns of labour market entry - long wait or career instability? An empirical comparison of Italy, Great Britain and West Germany. European Sociological Review, 21(5), 427-440.

Scherer, S., \& Reyneri, E. (2008). Come È Cresciuta L'occupazione Femminile in Italia: Fattori Strutturali E Culturali a Confronto. Stato E Mercato 183-9701.

Skoog, G. R., \& Ciecka, J. E. (2010). Measuring years of inactivity, years in retirement, time to retirement, and age at retirement within the Markov model. Demography, 47(3), 609-628.

Smith, S. J. (1986). Worklife estimates: Effects of race and education. Washington: US Department of Labor, Bureau of Labor Statistics.

Taylor, J., \& Bradley, S. (1997). Unemployment in Europe: A comparative analysis of regional disparities in Germany, Italy and the UK. Kyklos, 50(2), 221-245. https://doi.org/10.1111/1467-6435.00012).

Taylor, H. M., \& Karlin, S. (1998). An introduction to stochastic modeling. Academic. Retrieved (https:// books.google.de/books?id=UtPgVrVthF8C).

Venn, D. (2012). Eligibility criteria for unemployment benefits: Quantitative indicators for oecd and eu countries. In OECD social, employment and migration working papers, No. 131.

Warner, D. F., Hayward, M. D., \& Hardy, M. A. (2010). The retirement life course in America at the dawn of the twenty-first century. Population Research and Policy Review, 29(6), 893-919.

Wickham, H. (2009). ggplot2: Elegant graphics for data analysis. Springer, New York. Retrieved http:// ggplot2.org.

Wickham, H., Hester, J., \& Francois, R. (2016). Readr: read tabular data. Retrieved https://cran.r-proje ct.org/package $=$ readr.

Yee, T. W. (2010). The VGAM package for categorical data analysis. Journal of Statistical Software, 32(10), $1-34$. 